Please do not remove this page

RMIT

UNIVERSITY

\title{
Acute effects of static stretching on hip flexor and quadriceps flexibility, range of motion and foot speed in kicking a football
}

Young, W.; Clothier, P; Otago, L; Bruce, Lyndell; Liddell, D

https://researchrepository.rmit.edu.au/esploro/outputs/9921858246901341/filesAndLinks?institution=61RMIT_INST\&index=null

Young, W., Clothier, P., Otago, L., Bruce, L., \& Liddell, D. (2004). Acute effects of static stretching on hip flexor and quadriceps flexibility, range of motion and foot speed in kicking a football. Journal of Science \& Medicine in Sport, 7(1), 23-31. https://doi.org/10.1016/S1440-2440(04)80040-9

Document Version: Accepted Manuscript

Published Version: https://doi.org/10.1016/S1440-2440(04)80040-9 
Thank you for downloading this document from the RMIT Research Repository.

The RMIT Research Repository is an open access database showcasing the research outputs of RMIT University researchers.

RMIT Research Repository: http://researchbank.rmit.edu.au/

\section{Citation:}

Young, W, Clothier, P, Otago, L, Bruce, L and Liddell, D 2004, 'Acute effects of static stretching on hip flexor and quadriceps flexibility, range of motion and foot speed in kicking a football', Journal of Science \& Medicine in Sport, vol. 7, no. 1, pp. 23-31.

See this record in the RMIT Research Repository at:

https://researchbank.rmit.edu.au/view/rmit:31312

Version: Accepted Manuscript

Copyright Statement: (C) N/A

Link to Published Version:

http://dx.doi.org/10.1016/S1440-2440(04)80040-9 


\title{
Acute effects of static stretching on hip flexor and quadriceps flexibility, range of motion and foot speed in kicking a football
}

\author{
W Young, P Clothier, L Otago, L Bruce \& D Liddell
}

School of Human Movement and Sport Sciences, University of Ballart, Victoria, Australia.

\begin{abstract}
The purpose of this research was to determine the effect of static stretching in a warm-up on hip flexor and quadriceps flexibility as measured by a modified Thomas test and on range of motion (ROM) of the leg and foot speed at impact in kicking a football with maximum effort. Sixteen Australian Rules (AR) footballers performed two different warm-ups on different days. One warm-up involved five minutes of sub-maximum running followed by seven practice kicks, while the other also included 4.5 minutes static stretching of the hip flexors and quadriceps after the running. A modified Thomas test was conduced before and after each warm-up. Players performed maximum effort drop punt kicks into a net while being videotaped to determine the ROM of the kicking leg and foot speed at impact with the ball. There were no significant changes in flexibility $(p>0.05)$ as a result of either warm-up and there were no significant differences between the warm-ups in the kicking variables $(p>0.05)$. It was concluded that the Thomas test may not have been sensitive to possible acute changes in flexibility from the warm-ups, and that stretching had no influence on kicking ROM or foot speed, possibly because of the complexity of the kicking skill.
\end{abstract}

(J Sci Med Sport 2004;7:1:23-31)

\section{Introduction}

Static stretching is widely used as part of warm-ups for sport and exercise with the objectives of increasing the range of motion (ROM) at various joints to optimise performance and to reduce the risk of injury ${ }^{1,2}$. However the utility of stretching has been scrutinized recently in relation to performance ${ }^{3,4}$ and injury prevention ${ }^{5,6}$.

Recent research indicates that static stretching can produce significant decrements in the strength ${ }^{7,8,9}$ and power production ${ }^{10,11,12}$ of the stretched muscle groups. These findings have led some researchers to recommend against the practice of stretching prior to strength and power activities ${ }^{10,13}$. Although this evidence for stretch-induced decrements in performance is quite convincing, the activities that have been adversely affected have typically been ones such as vertical jumping where performance is unlikely to be limited by the ROM that can be achieved.

Static stretching has been found to be effective for increasing ROM at various joints such as the hip ${ }^{14,15}$. If the variables that limit ROM can be temporarily removed, performance in some activities may be achieved more efficiently. For example, Godges et $\mathrm{al}^{14}$ reported that in subjects with poor hip flexibility, six 
Acute effects of static stretching on hip flexor...

minutes of static stretching improved walking and running economy, presumably due to improved "neuromuscular balance". However, research on the influence of static stretching during warm-up on dynamic ROM during a sports activity is lacking.

Kicking for distance is an important skill for various football codes. In AR football, the ability to kick long distances with accuracy provides a clear advantage to the player. Kicking is a "throwlike" movement pattern where the speed at the most distal segment, the foot, is important for kick distance ${ }^{16}$. According to Luhtanen ${ }^{17}$, foot speed in a soccer kick is influenced by a sequential summation of forces from muscles acting around the pelvis, hip, knee and ankle joints. Generally the greater the distance over which the swinging leg can move, the greater the potential to achieve a high foot speed at the instant of impact with the ball. Therefore, if stretching during warm-up can produce a short-term increase in flexibility, it could potentially enhance the ROM achieved in kicking and, in turn, increase foot speed at impact.

Unlike vertical jumping, kicking distance may be potentially increased by stretching, if this warm-up activity increases the ROM of the hip and knee joints during the kick. However, if stretching has a negative influence on the power production of the stretched muscles, the overall impact of stretching during warm-up on kicking performance is difficult to predict. It has been suggested that stretching may acutely improve flexibility by reducing musculotendinous stiffness ${ }^{18,19}$, but it is this very effect that has been attributed to the worsening of rate of force developed in explosive muscle activities ${ }^{10,20,21}$. Therefore, the purpose of the present study was to determine the effect of static stretching during warm-up on hip and knee joint flexibility, ROM at the hip and knee joints and foot speed during kicking for distance.

\section{Methods}

\section{Subjects}

Sixteen males aged between 18-33 years volunteered to participate in the study. The project was approved by the University Ethics Committee and conformed to the Code of Ethics of the Declaration of Helsinki. All subjects provided informed consent in writing. All of the participants indicated that their right leg was the preferred kicking leg, and were all required to have played AR football competitively in the last 12 months and to be free of any injury or disorder that could limit their participation.

\section{Experimental design}

The subjects attended the laboratory on three occasions. The first was for familiarisation of all of the procedures and the others were for data collection. Each player performed six maximum effort kicks following two different warmups on different days 1-3 days apart in a random order. Immediately before and after each warm-up, the player was assessed for hip flexor and quadriceps flexibility by a modified Thomas test. A control warm-up consisted of submaximum running and seven kicks of the football at 50-100\% of maximum effort. The experimental warm-up was the same as the control condition but included static stretching of the hip flexors and quadriceps between the submaximum running and kicking. This warm-up was performed because it contains the three components of a warm-up (sub-maximum general activity, 
stretching and practice of the specific skill) typically used by athletes prior to exercise or competition.

\section{Procedures}

On arrival at the laboratory for data collection, the subject was prepared by marking various landmarks with a semi-permanent pen and attaching reflective motion analysis markers on these points. The markers were placed in the following positions: iliac crest; hip (trochanterion); lateral knee (femur/tibia joint line); ankle (lateral malleolus); heel (calcaneous) and the foot (head of 5th metatarsal). These markings were used to generate a stick figure to identify pelvic, thigh, shank and foot positions and corresponding joint angles for the Thomas test and football kicking.

\section{Modified Thomas test}

The subject lay supine on a table so that the gluteal fold was located at the end of the table and he held both knees to the chest. Then the right leg was lowered until it came to rest and the subject was instructed to keep the leg as relaxed as possible. Thomas test joint angles were calculated from a leg position corresponding with a posterior pelvic tilt (lumbar spine on table), and was defined as a horizontal alignment of the iliac crest and trochanterion landmarks. If the alignment was judged as not being horizontal, the subject was asked to move the contralateral knee closer to or further from the chest. For example, bringing the knee closer to the chest produced flexion of the lumbar spine (Figure 1). This stationary body position was videotaped for approximately three seconds. Video images were recorded using a Panasonic MS5 S-VHS video camcorder, set to operate at $25 \mathrm{~Hz}$. The camera was positioned $11.5 \mathrm{~m}$ perpendicular to the plane of motion of the leg. An exposure time of $500 . \mathrm{s}^{-1}$ was used and the video images were recorded on a Panasonic VCR (model AG-7350-E).

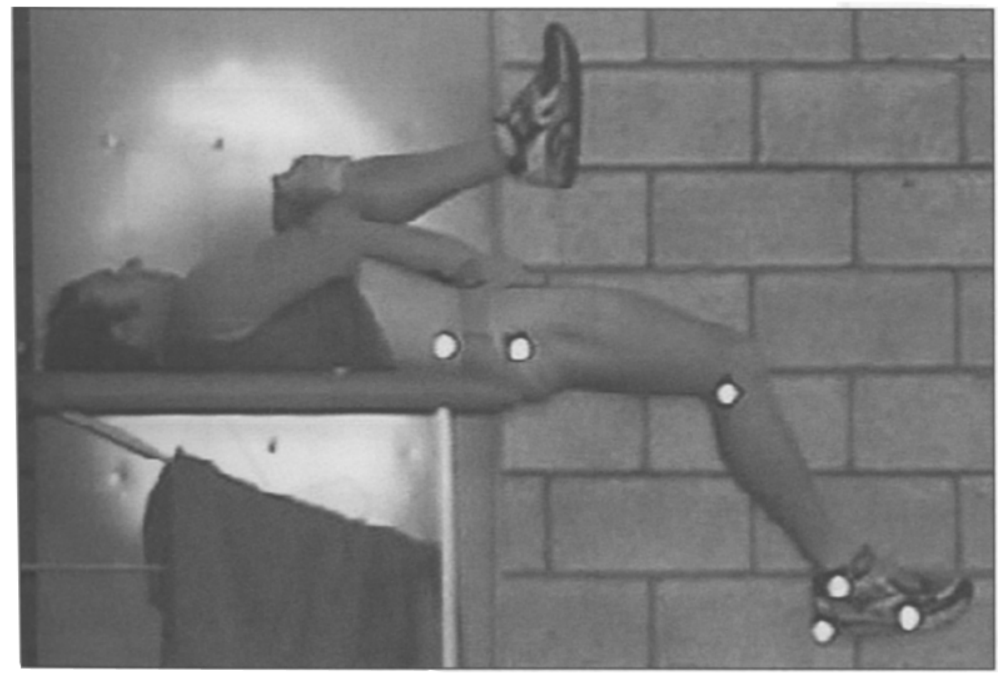

Figure 1: Modified Thomas test. 
Acute effects of static stretching on hip flexor...

\section{Warm-ups}

Both warm-ups began with a five minute run at $10 \mathrm{~km} / \mathrm{hr}$ on a treadmill. During the familiarisation session, participants were asked to nominate a running pace that was usual for them during a five minute warm-up as the treadmill speed was gradually increased. As the speeds selected were all within $10 \%$ of $10 \mathrm{~km} / \mathrm{hr}$, this speed was used for all participants.

For the experimental warm-up, three static stretching exercises for the hip flexors and quadriceps muscles were then performed consisting of three repetitions of ' $30 \mathrm{~s}$ each side in an alternating order for each exercise. In the first exercise, the subject lay in a prone position with the thigh of the stretched leg resting on a wedge to hyperextend the hip. One of the investigators slowly moved the ankle to flex the knee (Figure 2A). The second exercise required the subject to place one foot in front of the body and the knee of the other leg on the floor so that the hip was in hyperextension. The lower leg was again moved to produce maximum knee flexion (Figure 2B). In the third stretch for the psoas muscles, the subject adopted a standing split position (with one foot forward and one backward) and lowered the body to achieve maximum hip

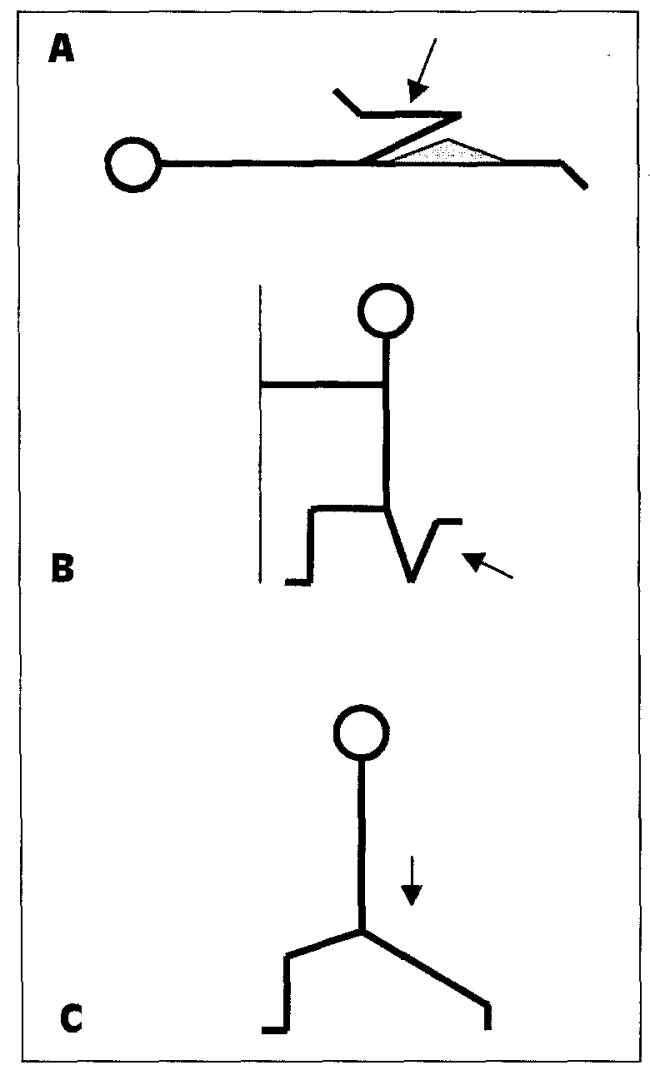

Figure 2: Body positions for static stretching exercises. 
hyperextension with the knee extended while maintaining a neutral pelvic position (Figure 2C). In all stretches, the limb was slowly moved to the end of the ROM without pain, as indicated by the subject and held in that position by one of the investigators for $30 \mathrm{~s}$ (Figure 2). Finally for both warm-ups, the participants performed seven drop punt kicks into a net; one at 50,60, 70, 80, 90, 95 and $100 \%$ of their perceived maximum effort. Immediately after the warm-ups, the modified Thomas test was again conducted to determine the influence of the warm-up conditions on ROM.

\section{Kicking}

Following the Thomas test, the participants performed six maximum effort drop punt kicks with the right foot in the laboratory into a net approximately $10 \mathrm{~m}$ away.

Kicking trials were recorded using a Peak video camcorder (HSC-200PS) set to record at $200 \mathrm{~Hz}$. An exposure time of $1000 . \mathrm{s}^{-1}$ was used and the video images were recorded on a Panasonic VCR (model AG-5700). This camera was positioned $13.5 \mathrm{~m}$ perpendicular to the plane of motion of the leg during kicking.

\section{Analysis of flexibility and kicking variables}

Two-dimensional analysis via a Peak Motus 32 (Version 6.1) motion analysis system was performed on all recorded video images. All six landmarks for each test trial were digitised using a combination of automatic and manual methods. The iliac crest, trochanterion, knee and ankle were digitised from which hip and knee flexion angles were calculated from the Thomas test. If the thigh position was lower than the horizontal line made by the iliac crest and trochanterion, the hip was considered to be hyperextended, and the angle recorded was given a positive value. The knee angle was expressed as the amount of knee flexion.

Kicking trials were digitised from last foot contact with the ground to ball contact, of the kicking leg. Foot speed at contact was measured as the speed of

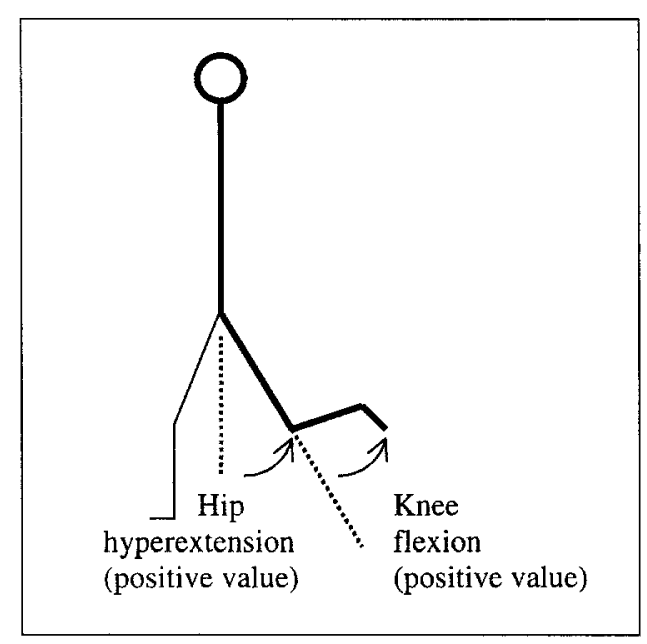

Figure 3. Definition of values assigned to thigh and lower leg positions of the kicking limb. 
Acute effects of static stretching on hip flexor...

the foot (head of 5th metatarsal) immediately prior to ball contact. Computed data were smoothed using a Butterworth filter with a prescribed cut-off of 10 Hz. It is possible that this procedure could have over smoothed the true velocity value at impact. However, we suggest that the data obtained were acceptable for two reasons. First, the deceleration of the foot resulting from impact would be expected to be relatively small due to the small mass of the ball. Second, the error would be systematic rather than random, which would not influence the statistical comparison of the warm-up conditions.

All kicking trials were digitised with the trial containing the greatest foot velocity prior to contact retained for analysis. Kicking variables were generated to describe the ROM of the leg (Figure 3).

The accuracy of the digitising process was enhanced by using the magnifier function of the analysis system, which increases the size of the reflected markers. To check for the repeatability of the digitising for the Thomas test, a trial for one subject was repeated ten times. This yielded a coefficient of variation of $2.5 \%$ and $0.9 \%$ for the hip and knee angles, respectively.

\section{Statistics}

A repeated measures MANOVA was used to determine if there was a difference between the warm-up conditions in flexibility over time. Paired T-tests were conducted to identify if there were any differences between the warm-up conditions in the kicking variables. Statistical significance was accepted at the $\mathrm{p}<0.05$ level.

\section{Results}

The mean changes in hip and knee flexibility as a result of each warm-up are shown in Table 1 . While there was a trend for the stretch warm-up to produce greater gains in flexibility, there were no statistically significant time effects (pre- to post-warm-up) or interaction effects (warm-up $\mathrm{x}$ time) for the flexibility measures $(p>0.05)$. There were no significant differences between the warm-up conditions for any of the kicking variables (Table 2).

\begin{tabular}{|lccc|}
\hline & & Before warm-up & After warm-up \\
\hline Hip & Control (deg) & $12.0 \pm 7.8$ & $12.6 \pm 7.5$ \\
& Stretch (deg) & $12.3 \pm 6.6$ & $13.7 \pm 7.8$ \\
Knee & Control (deg) & $51.7 \pm 7.6$ & $53.4 \pm 10.3$ \\
& Stretch (deg) & $51.5 \pm 8.3$ & $49.8 \pm 7.7$ \\
\hline
\end{tabular}

Table 1: Mean \pm SD flexibility results from the Thomas test.

\begin{tabular}{|lcc|}
\hline & control & stretch \\
\hline Max hip extension angle (deg) & $8.3 \pm 4.3$ & $8.0 \pm 5.2$ \\
Knee flexion angle at max hip angle (deg) & $68.6 \pm 15.9$ & $69.1 \pm 17.6$ \\
Maximum knee flexion angle (deg) & $108.7 \pm 10.4$ & $107.8 \pm 9.2$ \\
Hip at max knee flexion angle (deg) & $-5.5 \pm 4.9$ & $-5.5 \pm 6.8$ \\
Foot speed at impact (m/s) & $20.6 \pm 0.9$ & $20.7 \pm 0.8$ \\
\hline
\end{tabular}

Table 2: Mean $\pm S D$ results for kicking variables. 


\section{Discussion}

The finding that neither warm-up was able to elicit a significant increase in hip or knee flexibility was somewhat surprising. Sub-maximum running on its own has been shown to be ineffective for increasing ROM at the ankle joint ${ }^{22}$ and at the knee joint 23 . However, static stretching has been reported to produce significant short-term gains in flexibility in the plantar flexors ${ }^{11,22}$ and hamstrings ${ }^{9,15,23}$. When static stretching and running are combined in the warm-up, flexibility has been found to increase but not significantly more than stretching alone ${ }^{22,23}$. This previous research suggests that stretching is more influential than running for acutely increasing flexibility at some joints.

The influence of the seven practice kicks on ROM is unknown. The kicks may be considered as a form of dynamic stretching which could potentially enhance flexibility. However, it is unlikely that they caused the hip to be extended or the knee to be flexed to the end of the ROM. Further, these kicks would have involved significant muscle contractions which could possibly have a negative influence on $\mathrm{ROM}^{24}$ in subsequent kicks. This may partly contribute to the lack of increased flexibility from the warm-ups, especially the control condition.

There is limited research using a form of Thomas test to describe hip and knee flexibility following warm-ups. However, Godges et $\mathrm{al}^{14}$ reported that six minutes of static stretching of the hip flexors produced a significant increase of $4^{\circ}$ in hip extension. The discrepancy between this finding and the present study might be explained by a number of factors. The study by Godges et al used subjects who had limited hip flexor flexibility; that is, they were not able to reach a position of full hip extension in the Thomas test. It is possible that a stretching routine is more effective for individuals with "tight" muscles or relatively poor flexibility. The subjects in the present study had hip flexibility comparable to other healthy sports people ${ }^{25}$. Secondly, in the present study, the stretching routine lasted 4.5 minutes with the stretches shared between the hip flexor and quadriceps muscle groups. The subjects in the study by Godges et al stretched the hip flexors for a total of six minutes.

Another explanation for the lack of significant gain in hip and knee flexibility emanating from the warm-ups in the present study may reside in the nature of the Thomas test. In this study, we instructed each subject to relax the muscles and allow the tested limb to hang freely, as done by others ${ }^{25,26}$. This procedure relies on the weight of the leg to provide the stretching force, which is different to most tests of flexibility that allow an external force to move the limb to the end of the range of motion. It is easy to demonstrate with this Thomas test procedure that additional force applied to the thigh will move the leg to a greater ROM. Therefore, we suggest that the Thomas test as conducted in the present study should be questioned as a valid measure of the maximum ROM achievable (flexibility). It is possible that a different test of hip flexor and quadriceps flexibility would have been more sensitive to the warm-ups used in this study.

Based on the above discussion, it cannot be discounted that the warm-ups achieved some acute increase in maximum ROM at the hip and knee joints that was not detected. The question of interest is whether or not the warm-ups differed in their influence on ROM and final foot speed in kicking. The results indicated no significant differences between the warm-up conditions on any of 
these variables (Table 2), suggesting that stretching had no influence on kicking kinematics. Even if there were differences between the warm-ups in flexibility not detected by the Thomas test, the results indicate that such possible differences would have had no effect on the ROM of the swinging leg and foot speed in kicking. If a warm-up is able to induce an acute increase in ROM based on a static test of flexibility, it is possible that this may not automatically transfer to an altered ROM in a complex multi-segment dynamic activity such as kicking. It is likely that, in a well-learned kicking skill, the movement pattern is resistant to any possible changes to the stiffness of the muscle or connective tissues. In the present study, maximum hip extension reached $13.7^{\circ}$ after the stretch warm-up based on the Thomas test, whereas the corresponding value during the kick was only $8^{\circ}$ (Tables $1 \& 2$ ). This indicates that the kicking leg was not taken to the end of its ROM at the end of the back swing. Therefore, stretching and warm-up in general may be expected to have limited impact on the maximum hip extension and knee flexion achieved during the kick.

Previous research has demonstrated that static stretching for about 1.5-4 minutes can inhibit muscle power performance ${ }^{11,13,27}$. The present study did not use any tests of hip flexor and quadriceps power and therefore does not provide any insight into whether or not the warm-up including static stretching had any detrimental effect on explosive force production. It could be speculated that such a decrement in power might be reflected in a reduction in foot speed since the hip flexors and quadriceps have been shown to be highly active in kicking $^{28}$. However, the foot speed at impact with the ball is a function of complex neuromuscular patterns from many other muscles ${ }^{28}$. Further research should attempt to isolate the muscle performance of the stretched muscle groups.

\section{Conclusion}

The present study showed that a warm-up containing running and practice kicks with or without the inclusion of static stretching produced no change in flexibility of the hip flexors and quadriceps, as measured by a modified Thomas test. It is concluded that the Thomas test used in this study may be insensitive to potential acute changes in flexibility and has limited value in monitoring the maximum ROM capability of an individual. The inclusion of static stretching in a warm-up had no influence on the ROM of the swinging leg during kicking or the foot speed at impact with the ball. It was concluded that any short-term changes in flexibility may not be reflected in the kinematics of kicking because of the complexity and multi-factorial nature of this skill.

\section{References}

1. McArdle WD, Katch FI, \& Katch VI. Exercise Physiology (3rd ed). Philadelphia. Lea and Febiger. 1991.

2. Safran MR, Garrett, WE, Seaber AV. et al. The role of warmup in muscular injury prevention. Am J Sports Med 1988;16(2): 123-128.

3. Knudson D. Stretching during warm-up. Do we have enough evidence? JOPERD 1999; 7O(7): 24-27.

4. Young WB \& Behm DG. Should static stretching be used during a warm-up for strength and power activities? Stren Cond $J$ 2002; 24(6): 33-37.

5. Shrier I. Stretching before exercise does not reduce the risk of local muscle injury: a critical review of the clinical and basic science literature. Clin J Sports Med 1999; 9: 221-227. 
6. Pope RP, Herbert RD, Kirwan JD et al. A randomized trial of preexercise stretching for prevention of lower-limb injury. Med Sci Sports Exerc 2000; 32(2): 271-277.

7. Behm DG, Button DC \& Butt JC. Factors affecting force loss with prolonged stretching. Can $J$ Appl Physiol 2001; 26(3): 262-272.

8. Fowles JR, Sale DG \& MacDougall JD. Reduced strength after passive stretch of the human plantarflexors. J Appl Physiol 2000; 89: 1179-1188.

9. Kokkonen J, Nelson AG, \& Cornwell A. Acute muscle stretching inhibits maximal strength performance. Res $Q$ Exerc Sport 1998; 69(4): 411-415.

10. Cornwell A, Nelson G, Heise GD et al. Acute effects of passive muscle stretching on vertical jump performance. J Hum Mov Stud 2001; 40: 307-324.

11. Cornwell A, Nelson AG, \& Sidaway B. Acute effects of stretching on the neuromechanical properties of the triceps surae muscle complex. Eur $J$ Appl Physiol 2002; 86: 428-434.

12. Young W, \& Elliott $\mathrm{S}$. Acute effects of static stretching, proprioceptive neuromuscular facilitation stretching, and maximum voluntary contractions on explosive force production and jumping performance. Res Buart Exerc Sport 2001; 72(3): 273-279.

13. McLellan EW. The effect of static stretching on peak power and peak velocity during the bench press. Masters Thesis 2000; University of Memphis.

14. Godges JJ, MacRae H, Longdon C. et al. The effects of two stretching procedures on hip range of motion and gait economy. JOSPT 1989; 10:350-357.

15. Wiemann K, \& Hahn K. Influences of strength, stretching and circulatory exercises on flexibility parameters of the human hamstrings. Int $J$ Sports Med 1997; 18: 340-346.

16. Kreighbaum E, \& Barthels KM. Biomechanics A Qualitative Approach for Studying Human Movement. 2nd ed. New York. MacMillan. 1985.

17. Luhtanen P. Kinematics and kinetics of maximal instep kicking in junior soccer players. In Science and Football. Reilly T, Lees A, Davids K \& W Murphy. (Eds) London. E \& FN Spon. 1988.

18. Magnusson SP. Passive properties of human skeletal muscle during stretch maneuvers. Scand J Med Sci Sports 1998; 8: 65-77.

19. Magnusson SP, Simonsen EB, Aagaard P et al. Biomechanical responses to repeated stretches in human hamstring muscle in vivo. Am J Sports Med 1996; 24(5): 622-627.

20. Nelson AG, Allen JD, Cornwell A et al. Inhibition of maximal voluntary isometric torque production by acute stretching is joint-angle specific. Res $Q$ Exerc Sport 2001; 72(1): 68-70.

21. Nelson AG, Guillory IK, Cornwell A. et al. Inhibition of maximal voluntary isokinetic torque production following stretching is velocity-specific. Journal Stren Cond Res 2001; 15(2): 241246.

22. McNair PJ, \& Stanley SN. Effect of passive stretching and jogging on the series elastic muscle stiffness and range of motion of the ankle joint. Br J Sports Med 1996; 30: 313-318.

23. Gillette TM, Holland JG, Vincent WJ, et al. Relationship of body core temperature and warm-up to knee range of motion. JOSPT 1991; 13(3): 126-131.

24. Gill T, Wilkinson A, Edwards E, Grimmer K. The effect of either a pre or post exercise stretch on straight leg raise range of motion (SLR-ROM) in females. J Sci Med Sport 5(4): 281290 .

25. Harvey D. Assessment of the flexibility of elite athletes using the modified Thomas test. $\mathrm{Br}$ $J$ Sports Med 1998; 32: 68-70.

26. Schache AG, Blanch PD, \& Murphy AT. Relation of anterior pelvic tilt during running to clinical and kinematic measures of hip extension. Br J Sports Med 2000; 34: 279-283.

27. Young WB, \& Behm DG. Effects of running, static stretching and practice jumps on explosive force production and jumping performance. J Sports Med Phys Fitness 2003; 43(1): 21-7.

28. Orchard J, Walt S, McIntosh A. et al. Muscle activity during the drop punt kick. In Science and football $N$. Spinks W, Reilly T, \& Murphy A. (Eds). London. Routledge. 2002. 